\title{
Comparison of autologous hematopoietic cell transplantation performed in tandem and in disease relapse in multiple myeloma patients
}

\author{
A. JUNGOVA ${ }^{*, *}$, S. VOKURKA ${ }^{*}$, M. SCHUTZOVA, K. STEINEROVA, L. MOHAMMADOVA, M. KARAS, D. LYSAK, P. JINDRA \\ Department of Hematology and Oncology, University Hospital in Pilsen, Charles University, Pilsen, Czech Republic \\ *Correspondence: jungovaa@fnplzen.cz \\ ${ }^{\#}$ Contributed equally to this work.
}

Received May 11, 2017 / Accepted November 14, 2017

\begin{abstract}
Multiple myeloma is a malignant hemato-oncological malignancy that affects up to 600 people in the Czech Republic every year. Treatment options are under constant improvement and the autologous hematopoietic cell transplantation (Tx) remains a part of treatment protocols. Despite modern drug administration, the autologous Tx keeps its irreplaceable position and when ensuring two autologous Tx, the studies confirm a survival time more than twice as long as in non-transplant patients. However, there are no standardized procedures specifying the period in between the transplantations in more detail. Within our group, we compared the total of 66 patients who were administered a double transplant. One group underwent both planned tandem autologous Tx within a median of six months and mostly achieved just partial remission (PR) and less after the first transplant and out of disease progression. The other group only underwent the second Tx within a median of up to 14 months during a progression period or disease relapse. Both groups were comparable as far as basic parameters are concerned (age, type of induction therapy and cytogenetic risk). A significantly better treatment free survival (TFX) and overall survival (OS) were observed in the group where tandem Tx was administered. TFS was 18 months and median OS was not reached for the group of patients who received tandem Tx, while TFS was 10 months $(\mathrm{p}=0.04)$ and median OS was 57 months $(\mathrm{p}=0.005)$ for those who received delayed second Tx. In the group of patients who received second Tx during relapse, we observed that TFS and OS were shorter in those with a higher paraprotein level, thus suggesting the potential role of paraprotein level as a prognostic marker. The TFS in the subgroup with a high initial level was 4 months vs. 11 months ( $\mathrm{p}=0.0016)$ and OS 44 months vs. 65 months $(\mathrm{p}=0.03)$.
\end{abstract}

Key words: multiple myeloma, autologous transplant, tandem, melphalan

Multiple myeloma (MM) accounts for approximately $15 \%$ of hemato-oncological malignancies and up to $1 \%$ of all cancer diseases in the European population. In the Czech Republic, up to 600 patients are affected and the most common occurrence is in patients over 60 years of age (at this age the incidence is 1-4 persons/100 000 inhabitants a year), but the incidence relatively soars at ages over 75 (even up to16 persons/100 000 inhabitants) [1]. The induction therapy is based on a combination of modern drugs such as thalidomide, bortezomib or lenalidomide combined with corticoids and alternatively with alkylating agents or anthracyclines [2]. As a rule, 4 cycles of induction chemotherapy are administered followed by a peripheral blood stem cells (PBSC) mobilization (up to 65 years of age and in the elderly only if they are in good clinical condition). If the PBSC separation is successful, ideally with blood collection for 2 autologous transplantations, the first autologous Tx follows within 3-6 months. Further strategy then depends on the customs of the department, and there is no standard procedure recommended for a double Tx administration $[3,4]$. In the Czech Republic, a tandem Tx is used to obtain the best disease response (CMG recommendations for multiple myeloma treatment, paragraph 9.4). Our primary aim is to study the clinical responses and survival benefits of two different tx strategies and our secondary aim is to assess the role of paraprotein level in predicting survival. Our secondary aim includes verifying the paraprotein level in the treatment results obtained.

\section{Patients and methods}

The retrospective analysis of patients with $\mathrm{MM}$ was aimed at comparing the time before the beginning of the treatment after the last autologous Tx (TFS) and the overall survival 
(OS) in two groups of patients with a different administration scheme for the second autologous peripheral blood stem cell transplantation. In total, there were 66 patients with MM involved in the analysis and treated in our department from 2003 to 2014. All patients underwent 4 cycles of induction chemotherapy, most often in accordance with protocol CTD or VAD and also CVD (alternatively VD) see Table 1. All patients underwent successful mobilization with cyclophosphamide (HD-CPA $2.5 \mathrm{~g} / \mathrm{m}^{2}$ ) followed by a G-CSF (filgrastim) stimulation (Neupogen, Amgen, dose of $10 \mu \mathrm{g} / \mathrm{kg} /$ day) and all were given a graft of peripheral blood stem cells sufficient to ensure two administrations of a highdose chemotherapy with an autologous Tx. As a pre-transplant preparatory protocol, melphalan was administered in a one-off daily dose of $200 \mathrm{mg} / \mathrm{m}^{2}$ and this was reduced to $140 \mathrm{mg} / \mathrm{m}^{2}$ in patients over 65 years of age [6] or in renal insufficiency, while the protocol remained identical in every patient during both transplantations.

Allocation of patients into cohorts. The patients were all planned for at least single ASCT. Patients who did not reach at least a very good partial response (VGPR) after the 1st transplantation were directed to tandem ASCT. Moreover, patients with unfavorable prognostic profile (poor cytogenetics - $t$ (4;14), monosomy 13, p53 changes and extramedullary disease) were also assigned to tandem, regardless of the response achieved.

In the first compared group, there were 28 patients analyzed who obtained a partial remission (PR) and less after the $1^{\text {st }}$ autologous Tx (only 5 patients (18\%) obtained a VGPR but all these patients had unfavorable cytogenetics and we aimed at the greatest disease response possible) - and thus, the majority of patients showed a detectable disease persisting at a relatively considerable level. According to the plan, this group was administered tandem autologous $\mathrm{Tx}$ within a median of $5.5(2-11)$ months, and at the time of the second $\mathrm{Tx}$ administration there was no patient in disease progression.

The second group included 38 patients who were only monitored after the first autologous $\mathrm{Tx}$ and reached a CR and VGPR (66\% of the patients in this group). The remaining patients in the group achieved PR but some patients faced early progression within 6 months after the 1st Tx, some refused the planned Tx and some were not able to undergo the tandem $\mathrm{Tx}$ at the planned time. Therefore, these patients were indicated to receive the second Tx in the phase of relapsed/progressed myeloma and they were not administered any re-induction therapy. Within the scope of the sub-analysis, we divided this group into two subgroups with respect to the paraprotein values before the second $\mathrm{Tx}$, while arbitrarily setting the cut-off value of the 'low paraprotein level' to $10 \mathrm{~g} / \mathrm{l}$, alternatively $1000 \mathrm{mg} / \mathrm{l}$ in multiple myeloma (MM) with production of immunoglobulin light chains. The median paraprotein level was $6.8(2-40 \mathrm{~g} / \mathrm{l})$ in the first group or $250 \mathrm{mg} / \mathrm{l}$ for light chain myeloma (only 1 patient in this group), for the second group it was $9.2(2-29.6 \mathrm{~g} / \mathrm{l})$ and $719(400-792 \mathrm{mg} / \mathrm{l})$. Three patients with extra-medullary disease had higher paraprotein levels and were evaluated as 'high level'.

The comparison of the basic parameters in both groups (age, sex, ISS disease score, cytogenetic findings, type of induction therapy) did not show any statistically significant difference (Table 1). Subgroup characteristics in patients transplanted in disease relapse according to the initial paraprotein level are shown in Table 2.

The TFS period was defined as number of months from the $2^{\text {nd }}$ autologous $\mathrm{Tx}$ administration to the beginning of another treatment line started due to disease progression or relapse. The OS period was defined in the standard way as the time from diagnosis to the last follow-up (including death).

Statistical procedure. This was performed by program GraphPad InStat - Statistica Software and basic statistical tests - Mann-Whitney, Fisher's Exact Test and t-test. The Kaplan-Meier method was used to process TFS curves and probability of progression curves and the log-rank test (MedCalc software) was used to assess statistically significant differences. The differences between groups were tested at a significance level of $95 \%$; and values $\mathrm{p}<0.05$ were considered statistically significant.

Table 1. Patient characteristics in the whole group.

\begin{tabular}{|c|c|c|c|}
\hline & $\begin{array}{l}\text { Tandem } \\
(\mathrm{n}=28)\end{array}$ & $\begin{array}{l}\text { Tx in relapse } \\
(n=38)\end{array}$ & p-value \\
\hline Sex, male/female & $14 / 14$ & $17 / 21$ & $\mathrm{p}=0.13$ \\
\hline $\begin{array}{l}\text { Age at the time of diagno- } \\
\text { sis - median ( } \min -\max )\end{array}$ & $59(41-69)$ & $59(45-69)$ & $\mathrm{p}=0.36$ \\
\hline Observation Median & $46.5(21-165)$ & $33(20-112)$ & $\mathrm{p}=0.36$ \\
\hline \multicolumn{4}{|c|}{ ISS stage at the time of diagnosis } \\
\hline 1 & $8(29 \%)$ & $14(37 \%)$ & $\mathrm{p}=0.80$ \\
\hline 2 & $9(32 \%)$ & $9(24 \%)$ & $\mathrm{p}=0.60$ \\
\hline 3 & $11(39 \%)$ & $15(39 \%)$ & $\mathrm{p}=1.00$ \\
\hline \multicolumn{4}{|l|}{ Genetics } \\
\hline normal karyotype & $2(7 \%)$ & $7(18 \%)$ & $\mathrm{p}=0.30$ \\
\hline $\mathrm{t}(4 ; 14)$ & $2(7 \%)$ & $3(8 \%)$ & $\mathrm{p}=0.17$ \\
\hline monosomy 13 & $6(21 \%)$ & $7(18 \%)$ & $\mathrm{p}=1.00$ \\
\hline p53 changes & $1(3 \%)$ & $0(0 \%)$ & $\mathrm{p}=0.43$ \\
\hline t $(11 ; 14)$, hyperdiploidy & $10(36 \%)$ & $8(22 \%)$ & $\mathrm{p}=0.42$ \\
\hline others or not performed & $7(26 \%)$ & $13(34 \%)$ & $\mathrm{p}=0.61$ \\
\hline \multicolumn{4}{|l|}{ Induction chemotherapy } \\
\hline CTD & $11(39 \%)$ & $13(34 \%)$ & $\mathrm{p}=0.81$ \\
\hline CVD, VD & $6(21 \%)$ & $12(32 \%)$ & $\mathrm{p}=0.59$ \\
\hline VAD & $10(36 \%)$ & $12(32 \%)$ & $\mathrm{p}=0.81$ \\
\hline $\mathrm{RD}$ & $1(4 \%)$ & $1(2 \%)$ & $\mathrm{p}=1.00$ \\
\hline \multicolumn{4}{|c|}{ Stage of the disease after induction } \\
\hline $\mathrm{CR}$ & $0(0 \%)$ & $9(24 \%)$ & $\mathrm{p}=0.02$ \\
\hline VGPR & $5(18 \%)$ & $16(42 \%)$ & $\mathrm{p}=0.20$ \\
\hline $\mathrm{PR}$ & $18(64 \%)$ & $13(34 \%)$ & $\mathrm{p}=0.19$ \\
\hline SD & $5(18 \%)$ & $0(0 \%)$ & $\mathrm{p}=0.02$ \\
\hline
\end{tabular}

Number of patients: 66 


\section{Results}

The comparison of the group of patients who were administered the second tandem autologous Tx with the group where the second autologous Tx was administered in relapse/ progression did not show any significant differences in the basic characteristics - age, sex, disease stage 3 according to ISS, cytogenetic profile - and there was no evident difference in the median of patient observation: 46.5 months $(21-165)$ vs. 33 months $(20-112) \mathrm{p}=0.36$. In October $2015,34 / 66$

Table 2. Sub-group characteristics in patients transplanted in disease relapse according to the initial paraprotein level after the $2^{\text {nd }}$ autologous $T x$.

\begin{tabular}{lccc}
\hline & $\begin{array}{c}\text { Low Para- } \\
\text { protein Level } \\
(\mathbf{n}=\mathbf{2 0})\end{array}$ & $\begin{array}{c}\text { High Para- } \\
\text { protein Level } \\
(\mathbf{n}=\mathbf{1 8})\end{array}$ & p-value \\
\hline Sex, male/female & $8 / 12$ & 9.9 & $\mathrm{p}=0.77$ \\
ISS Stage & $8(40 \%)$ & $5(28 \%)$ & $\mathrm{p}=0.75$ \\
1 & $3(15 \%)$ & $5(28 \%)$ & $\mathrm{p}=0.69$ \\
2 & $9(45 \%)$ & $8(44 \%)$ & $\mathrm{p}=1.00$ \\
3 & $4(20 \%)$ & $3(17 \%)$ & $\mathrm{p}=1.00$ \\
Genetics & $1(5 \%)$ & $2(11 \%)$ & $\mathrm{p}=0.60$ \\
normal karyotype & $5(25 \%)$ & $2(11 \%)$ & $\mathrm{p}=0.44$ \\
t $(4 ; 14)$ & 0 & 0 & \\
monosomy 13 & $5(25 \%)$ & $3(17 \%)$ & $\mathrm{p}=0.71$ \\
p53 changes & $5(25 \%)$ & $8(44 \%)$ & $\mathrm{p}=0.52$ \\
t (11;14), hyperdiploidia & & & \\
others or not performed & $10(50 \%)$ & $3(17 \%)$ & $\mathrm{p}=0.19$ \\
Induction chemotherapy & $4(20 \%)$ & $8(44 \%)$ & $\mathrm{p}=0.33$ \\
CTD & $6(30 \%)$ & $6(33 \%)$ & $\mathrm{p}=1.00$ \\
CVD, VD & 0 & $1(6 \%)$ & $\mathrm{p}=0.49$ \\
VAD & & &
\end{tabular}

Number of patients: 38 patients were alive (52\%), 32 patients died (48\%). Detailed information is shown in Table 1.

The median time before beginning another treatment line, TFS, was significantly shorter in patients receiving the second transplant in disease relapse: 10 months (3-199) vs. 18 months $(3-108)(\mathrm{p}=0.04)$ (Figure $1 \mathrm{~A})$ and a statistically significantly worse overall survival (OS) was evident: 57 months (18-199) vs. the median was not reached in the group transplanted in tandem, $\mathrm{p}=0.005$ (Figure 1B).

The sub-analysis of the group transplanted in disease relapse $(n=38)$ with respect to the paraprotein level ("low level" vs. "high level") showed evident influence of the paraprotein value and thus, of advanced disease on TFS and OS. The medians of both these characteristics were significantly shorter in the sub-group with a high initial value: 4 months (2-30) vs. 11 months (3-199), $\mathrm{p}=0.0016$ and 44 months (18-96) vs. 65 months (27-199), $\mathrm{p}=0.03$. (Figure 2).

\section{Discussion}

Multiple myeloma is an incurable aggressive hematooncological disease. The basic therapeutic procedure consists of administering induction therapy followed by a high-dose chemotherapy and autologous hematopoietic cell transplantation in the $1^{\text {st }}$ line [6-8]. The latest recommendations advise a therapy followed by consolidation [9] and alternatively a maintaining therapy $[4,7]$. However, this is not the standard procedure in our conditions, especially due to payment politics. Administering one or two autologous Tx is not yet standardized but it has been discussed in several clinical studies (IFM 94, MAG 95, Bologna, GIMEMA, HOVON) [11-15]. The largest study IFM 94 confirms the effect of the tandem transplant in patients who did not reach at least a VGPR or a better response after the first Tx $[11,16$, 17] (Table 3). According to the standardized procedures in

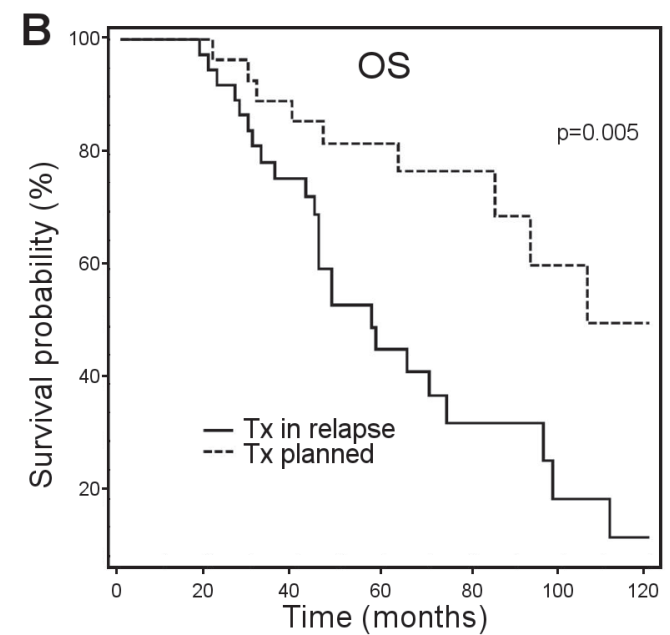

Figure 1. A: TFS comparison of the groups transplanted in tandem out of disease progression or only in disease relapse/progression ( $\mathrm{p}=0.04)$. B: OS comparison of the groups transplanted in tandem out of disease progression or only in disease relapse/progression $(\mathrm{p}=0.005)$. 

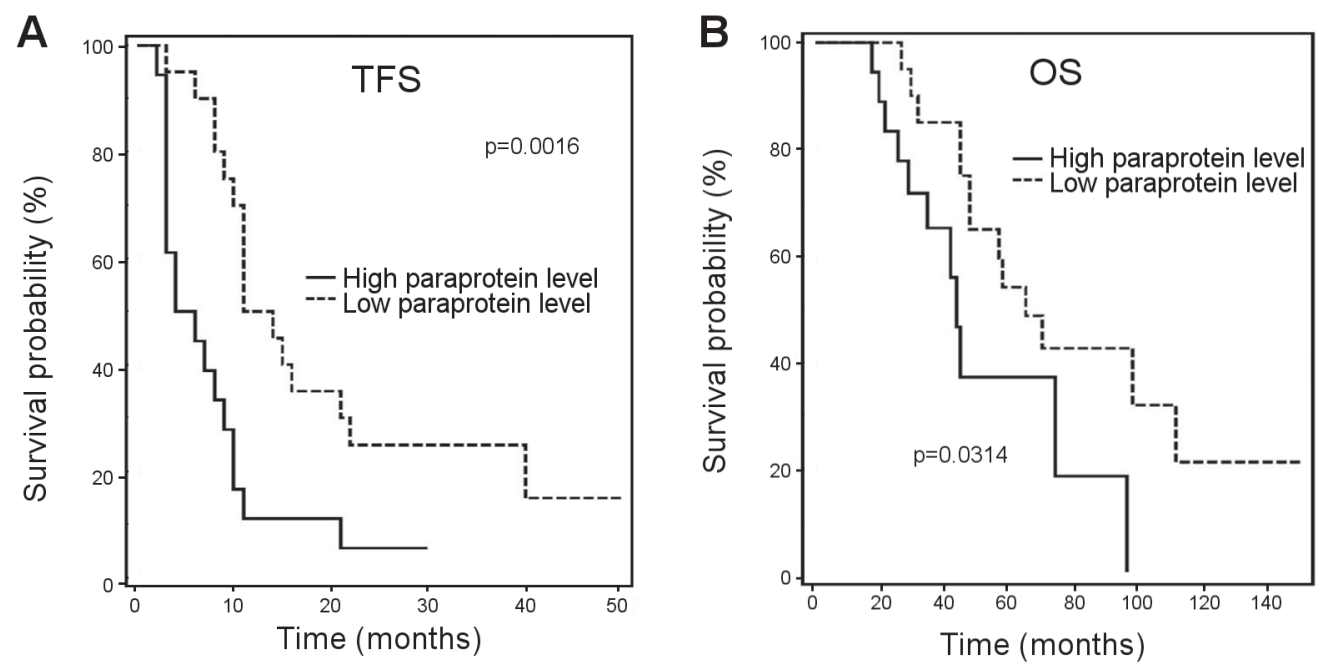

Figure 2. A: TFS in relation to the paraprotein level at the time of the 2 nd autologous $\mathrm{Tx}(\mathrm{p}=0.0016)$. B: OS in relation to the paraprotein level at the time of the 2nd autologous $\mathrm{Tx}$.

Table 3. EBMT criteria response to treatment.

\begin{tabular}{|c|c|c|}
\hline Response to treatment & EBMT criteria for common type & EBMT criteria for light chain \\
\hline SD (stable disease) & less than $25 \% \downarrow$ of monoclonal protein in the blood & \\
\hline MR (minimal response) & $\begin{array}{l}\text { between } 25 \text { and } 49 \% \downarrow \text { of monoclonal protein in the } \\
\text { blood }+50-89 \% \text { reduction in } 24 \mathrm{~h} \text { urinary light chain } \\
\text { excretion (monoclonal proteinuria }>200 \mathrm{mg} / \mathrm{d} \text { ) }\end{array}$ & $\begin{array}{l}50-89 \% \text { reduction in } 24 \mathrm{~h} \text { urinary light chain } \\
\text { excretion and monoclonal proteinuria }>200 \mathrm{mg} / \mathrm{d}\end{array}$ \\
\hline PR (partial remission) & $\begin{array}{l}\text { over } 50 \% \downarrow \text { of serum monoclonal protein }+>90 \% \text { reduc- } \\
\text { tion in } 24 \mathrm{~h} \text { urinary light chain excretion or M protein- } \\
\text { uria }<200 \mathrm{mg} / \mathrm{d}\end{array}$ & $\begin{array}{l}>90 \% \text { reduction in } 24 \mathrm{~h} \text { urinary light chain excre- } \\
\text { tion or monoclonal proteinuria }<200 \mathrm{mg} / \mathrm{d}\end{array}$ \\
\hline nCR - near Complete Response & Serum $\mathrm{MP}=0$, but Serum IF $>0$ & \\
\hline CR - complete response & $\begin{array}{l}\text { no monoclonal protein in the blood }+ \text { no serum/urine } \\
\text { monoclonal protein by Immunofixation }(\text { IF }<0)+<5 \% \\
\text { plasma cells in bone marrow aspirate }\end{array}$ & $\begin{array}{l}\text { partial response criteria }+ \text { no serum/urine mono- } \\
\text { clonal protein by immunofixation }(\mathrm{IF}<0)+<5 \% \\
\text { plasma cells in bone marrow aspirate }\end{array}$ \\
\hline
\end{tabular}

our department, we administer the second Tx either only in disease relapse / progression in patients who reach a CR or VGPR after the first autologous Tx or in the planned tandem mode in patients who reach only a PR or a worse response after the first Tx and are in a good clinical condition. The present study shows the results of analysis comparing the two different approaches to the indication of the second autologous Tx.

The total group of 66 patients showed statistically significantly better TFS and OS results in the group administered tandem autologous Tx (Figure 1): 10 vs. 18 months and 57 months vs. the median not reached in tandem Tx. All the other parameters (age, cytogenetics, initial induction) did not show any statistical differences in both groups (Table 2) and thus, the groups are comparable. Moreover, our patient group showed no evident bortezomib induction influence on TFS and OS [18], but only 18 patients were treated with bortezomib in induction. In view of the fact that this group only achieved a PR and less after the first Tx, it was expected that disease relapse would come in a relatively short period of time. Therefore, we administered the tandem Tx in patients who only achieved the SD after the first Tx, (5 patients), a PR (18 patients) and in only 5 patients with a VGPR. All these patients, however, had unfavorable cytogenetic findings (del 17p, monosomy 13).

Standard recommendations in acute relapse/progression advise administration of autologous Tx without re-induction [19]; in contrast, re-induction is suitable in slower progression. In our group, we compared patients according to progression level and aggressiveness; and patients in acute relapse (more than $10 \mathrm{~g} / \mathrm{l}$ or more than $1000 \mu \mathrm{g} / \mathrm{l}$ of light chains or extraosseous disease) had significantly worse TFS and OS.

The period of time before beginning the next treatment after Tx was within the median of 4 months in patients in acute relapse and 11 months in patients with slow progression, and 44 months vs. 65 months in overall survival. While acute relapse is an unfavorable factor in this disease, both groups have comparable parameters (age, induction regime, cytogenetic finding) and it is not possible to make any definite statement in this matter. Moreover, some acute relapses followed a CR, and this should be a favorable factor in OS, 
so the prognosis of the CR with a subsequent relapse remains arguable (negative - acute relapse/positive - achieving a CR).

We explain the longer TFS in the group who received a planned tandem administration by the deep remission after the $1^{\text {st }}$ autologous $\mathrm{Tx}$, although the response after induction was not ideal. This influence cannot be attributed to the type of induction therapy because treatments were otherwise the same in both patient groups. It was also not due to cytogenetic findings because these parameters are comparable in both groups. In the interim, there was no other treatment performed in either of the groups because re-induction was not standard practice in our department.

A longer OS in the tandem group must be connected to the given TFS values because 21 patients (75\%) in this group had TFS of over 1 year and 14 patients (50\%) showed a TFS of over 2 years. In contrast, there were only 12 patients (32\%) in the other group receiving no treatment within 1 year and 7 patients (18\%) for over 2 years. It was therefore necessary to start another treatment line sooner in the relapsed group and both remission period and time before further relapse was shorter. The OS length was not influenced by using different treatment regimes in these groups because the treatment protocols were identical in both.

This work aimed to contribute to the clarification of the 2 autologous Tx strategies in patients with multiple myeloma [19-21]. Although our analysis was limited by unicentric and retrospective observation with selection bias, the strategy stability of the treatment procedure in the entire patient group was advantageous. We now plan to implement analysis of treatment results in patients who undergo re-induction therapy because of progression/relapse before the second autologous Tx. This will confirm if re-induction influences the length of the remission period and, alternatively, the overall survival rate.

Our analytic results for the influence of paraprotein levels during relapse/progression before the second autologous Tx suggest that it would be more suitable to administer re-induction therapy first in patients with more advanced relapse/ progression and only then proceed with high-dose chemotherapy with an autologous Tx. Finally, we consider it more favorable to administer the second planned tandem autologous Tx without delay, and before further possible disease progression in those patients with higher remaining disease levels after the $1^{\text {st }} \mathrm{Tx}$. This would therefore be administered only at the stages of partial remission or stable disease.

Acknowledgements: Bone Marrow Transplant Foundation grant support for educational, laboratory and research purposes

\section{References}

[1] Electronic reference Czech myeloma group_Multiple Myeloma, statistics, CMG (Czech Myeloma Group) official website. http://www.myeloma.cz/index-en.php?pg=multiplemyeloma
[2] ROSINOL L, ORIOL A, TERUEL AI, HERNANDEZ D, LOPEZ-JIMENEZ J et al. Superiority of bortezomib, thalidomide, and dexamethasone (VTD) as induction pretransplantation therapy in multiple myeloma: a randomized phase 3 PETHEMA/GEM study. Blood 2012; 120: 1589-1596. https://doi.org/10.1182/blood-2012-02-408922

[3] CAVO M, SALWENDER H, ROSINOL L, MOREAU P, PETRUCCI MT et al. Double Vs Single Autologous Stem Cell Transplantation After Bortezomib-Based Induction Regimens For Multiple Myeloma: An Integrated Analysis Of Patient-Level Data From Phase European III Studies. Blood 2013; 122: 767. www.bloodjournal.org/content/122/21/767

[4] ATTAL M, HAROUSSEAU JL, FACON T, GUILHOT F, DOYEN C et al. Single versus double autologous stem-cell transplantation for multiple myeloma. N Engl J Med 2003; 349: 2495-2502. https://doi.org/10.1056/NEJMoa032290

[5] BADROS A, BARLOGIE B, SIEGEL E, MORRIS C, DESIKAN R et al. Autologous stem cell transplantation in elderly multiple myeloma patients over the age of 70 years. Br J Haematol 2001; 114: 600-607.

[6] BARLOGHIE B, JAGANNATH S, VESOLE D, NAUCKE S, CHESON B et al. Superiority of tandem autologous transplantation over standard therapy for previously untreated multiple myeloma. Blood 1997; 89: 789-793.

[7] CAVO M, RAJKUMAR SV, PALUMBO A, MOREAU $\mathrm{P}$, ORLOWSKI $\mathrm{R}$ et al. International Myeloma Working Group consensus approach to the treatment of multiple myeloma patients who are candidates for autologous stem cell transplantation. Blood 2011; 117: 6063-6073. https://doi. org/10.1182/blood-2011-02-297325

[8] CHILD JA, MORGAN GJ, DAVIES FE, OWEN RG, BELL SE et al. High-dose chemotherapy with hematopoietic stemcell rescue for multiple myeloma. N Engl J Med 2003; 348: 1875-1883. https://doi.org/10.1056/NEJMoa022340

[9] LADETTO M, PAGLIANO G, FERRERO S, CAVALLO F, DRANDI D et al. Major tumor shrinking and persistent molecular remissions after consolidation with bortezomib, thalidomide, and dexamethasone in patients with autografted myeloma. J Clin Oncol 2010; 28: 2077-2084. https://doi. org/10.1200/JCO.2009.23.7172

[10] ATTAL M, HAROUSSEAU JL, LEVYRAZ S, DOYEN C, HULIN C et al. Maintenance therapy with thalidomide improves survival in patients with multiple myeloma. Blood 2006; 108: 3289-3294. https://doi.org/10.1182/blood-2006-05-022962

[11] CAVO M, TOSI P, ZAMAGNI E, CELLINI C, TACCHETTI $\mathrm{P}$ et al. Prospective, randomized study of single compared with double autologous stem-cell transplantation for multiple myeloma: Bologna 96 clinical study. J Clin Oncol 2007; 25: 2434-2441. https://doi.org/10.1200/JCO.2006.10.2509

[12] MOREAU P, HULLIN C, GARBAN F, YAKOUB-AGHA I, BENBOUBKER L et al. Tandem autologous stem cell transplantation in high-risk de novo multiple myeloma: final results of the prospective and randomized IFM 99-04 protocol. Blood 2006; 107: 397-403. https://doi.org/10.1182/ blood-2005-06-2573 
[13] FERNAND JP, KATSAHIAN S, DIVINE M, LEBLOND V, DREYFUS F et al. High-dose therapy and autologous blood stem-cell transplantation compared with conventional treatment in myeloma patients aged 55 to 65 Years: Long-term results of a randomized control trial from the Group Myelome-Autogreffe. J Clin Oncol 2005; 23: 9227-9233. https:// doi.org/10.1200/JCO.2005.03.0551

[14] PALUMBO A, CAVALLO F, GAY F, DI RAIMONDO F, BEN YEHUDA D et al. Autologous transplantation and maintenance therapy in multiple myeloma. N Engl J Med 2014; 371: 895-905. https://doi.org/10.1056/NEJMoa1402888

[15] SONNEVELD P, VAN DER HOLT B, VELLENGA E, CROOCKEWIT S, VERHOEF $G$ et al. Intensive Versus Double Intensive Therapy in Untreated Multiple Myeloma: Final Analysis of the HOVON 24 Trial. Blood 2005; 106: 2545. www.bloodjournal.org/content/106/11/2545

[16] KREJCI M, HAJEK R, ADAM Z. Significant improvement of long-term survival after autologous transplantation in multiple myeloma patients: a single centre experience. Bone Marrow Transplant 2008; 41(Suppl.1): 1358.

[17] HAROUSSEAU JL. Stem cell transplantation in multiple myeloma (0, 1, or2). Curr Opin Oncol 2005; 17: 93-98. https:// doi.org/10.1097/01.cco.0000152978.32304.37
[18] HAROUSSEAU JL, ATTAL M, AVET-LOISEAU H, MARIT $\mathrm{G}$, CAILLOT D et al. Bortezomib plus dexamethasone is superior to vincristine plus doxorubicin plus dexamethasone as induction treatment prior to autologous stem-cell transplantation in newly diagnosed multiple myeloma: results of the IFM 2005-01 phase III trial. J Clin Oncol 2010, 28: 4621-4629. https://doi.org/10.1200/JCO.2009.27.9158

[19] Czech Myeloma Group. [Multiple Myeloma recommended treatment]. Transfuze Hematol Dnes 2012; 18 suppl 1: 6-89.

[20] ATTAL M, HARROUSSEAU JL, STOPPA AM, SOTTO JJ, FUZIBET JG et al. A prospective, randomized trial of autologous bone marrow transplantation and chemotherapy in multiple myeloma. Intergroupe Franćais du Myelome. N Engl J Med 1996; 335: 91-97. https://doi.org/10.1056/ NEJM199607113350204

[21] KUMAR SK, RAJKUMAR SV, DISPENZIERI A, LACY MQ, HAYMAN SR et al. Improved survival in multiple myeloma and the impact of novel therapies. Blood 2008; 111: 25162520. https://doi.org/10.1182/blood-2007-10-116129 